\title{
Ännu ett exempel på den stungna l-runan
}

\author{
Magnus Källström (Swedish National Heritage Board)
}

\begin{abstract}
The dotted $l$-rune (normally rendered as $\mathbf{L}$ ) is known from a few scattered inscriptions in various parts of Scandinavia. On Gotland this rune has previously been recorded in three medieval inscriptions (G 63, G 163 and $G$ 192). This short contribution focuses on one additional example from a grave-slab in Väte church, G 173, where the branch of one of the l-runes terminates in a round dot. No one has discussed this rune before, but it seems very likely that it represents a variant of the dotted $l$-rune and that the runic sequence in question should be transliterated as munduatz, representing the genitive of the male name Mundvaldr.
\end{abstract}

Keywords: medieval runes, dotted $l$-rune, G 173 Väte church, Gotland

Ten tidigare artikel i denna tidskrift (Källström 2016) behandlade jag Lnågra sällsynta medeltida runformer, bl.a. stungna $\mathbf{n}$ - och I-runor (translittererade $\mathbf{N}$ och $\mathbf{L}$ ). Den senare är företrädesvis känd från Gotland, där den föreligger i tre inskrifter: aLum allum G 63 Silte kyrka, kiaLera kiallera G 163 Mulde, Fröjels sn och aLlir allir G 192 Västergarns kyrka. Alessandro Palumbo (2012, 77) har även dragit fram exemplet alıra aldra på G 65 Sproge kyrka, men framhåller säkert helt riktigt att det här handlar om en d-runa som har blivit spegelvänd (flera förväntade t-runor i inskriften motsvaras nämligen av l-runor).

Vid ett besök i Väte kyrka på Gotland den 10 september 2019 uppmärksammade jag av en tillfällighet ytterligare ett exempel på den stungna I-runan (Källström 2019a), men här i den variant som hittills bara verkar vara känd genom två något osäkra belägg från fastlandet (Vg 219 och U STERIK2002;168, se Palumbo 2020, 211) samt på ett nyfunnet blyföre-

Källström, Magnus. "Ännu ett exempel på den stungna I-runan." Futhark: International fournal of Runic Studies 11 (2020, publ. 2021): 173-76. DOI: $10.33063 /$ diva- 438142 


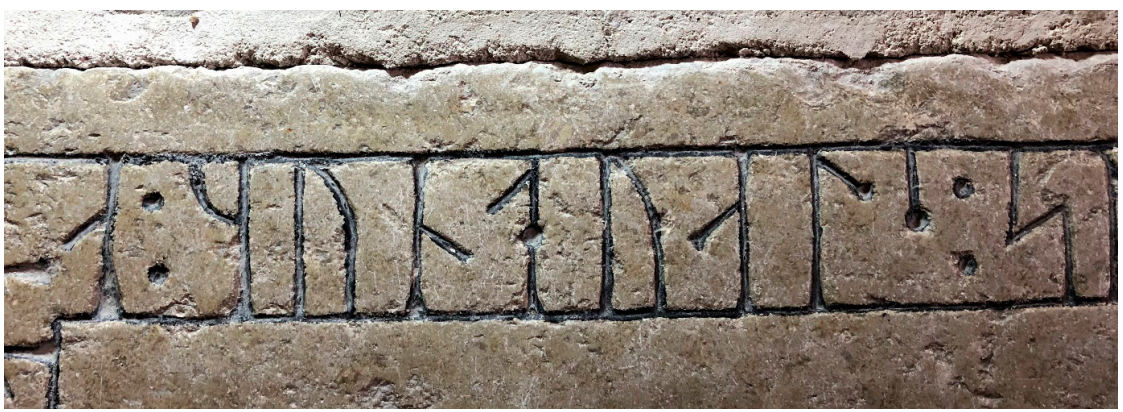

Fig. 1. Runföljden munduaLz på G 173 Väte kyrka. Foto: Magnus Källström, 2019.

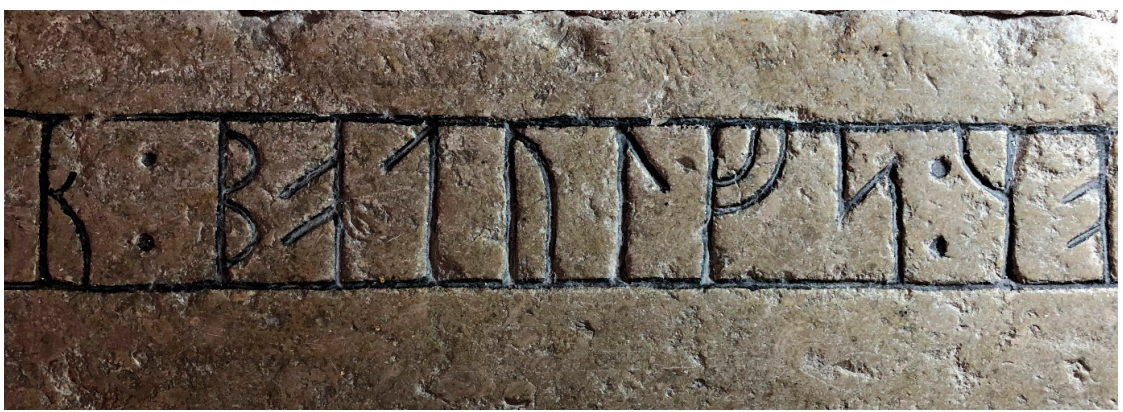

Fig. 2. Runföljden botulfs på G 173 Väte kyrka. Foto: Magnus Källström, 2019.

mål från Pryssgården i Norrköping (Källström 2019b). På gravhällen G 173 som ligger inlagd i golvet till koret förekommer en runföljd mundualz, där I-runan är försedd med en tydlig punkt i änden av bistaven (fig. 1). Denna detalj uppmärksammades redan av Elisabeth Svärdström (SRI, 12: 97), som i sin beskrivning av inskriftens teckenuppsättning skriver att runan "z [har] punktformig avslutning, likaså bistaven i 57 l'. Hon låter dock inte detta slå igenom i translittereringen och ger ingen ytterligare kommentar till varför l-runan har denna form. Förmodligen beror det på att många av inskriftens runor är försedda med seriffer och att hon har uppfattat denna punkt som ett rent dekorativt drag. Det finns dock ytterligare en I-runa i inskriften, nämligen i namnet botulfs, och här har inte bistaven någon punktavslutning (se fig. 2). Dessa omständigheter tillsammans med formen på punkten i den förstnämnda l-runan talar för att den är betydelsebärande och att runföljden i stället ska translittereras som mundualz. Runorna har tidigare tolkats som genitiv av ett mansnamn Mundvaldr (SRI, 12: 97) och valet av Z-runan beror säkert på att denna runa normalt har ljudvärdet [ts] i de gotländska runinskrifterna (se t.ex. Snædal 2002, 122). Den stungna I-runan uppträder alltså här före en dental konsonant. Detta svarar mot 
bruket i ordet skuLdi skuldi på Åkerfunten på Bornholm (DR 373), vilken ju som bekant är signerad av den gotländske stenmästaren Sigraf.

Runan z förekommer på G 173 även i ordet hanz hans, där den kan verka omotiverad, men motsvarande skrivningar förekommer även i ytterligare tre gotländska runinskrifter: hanz G 100 och hanz G 314 och [hanz], [-anz] G 315† (läsningen av den senare inskriften enligt en tidigare förbisedd teckning av Carl Säve från 1844 [Källström manus]). Thorgunn Snædal $(2002,212)$ menar att z-runan i fall som dessa "snarast" tycks "beteckna $s$ " och hänvisar till att runtecknet "i grunden är kortkvist-s". Det verkar dock sannolikare att dessa skrivningar har haft någon form av motsvarighet i uttalet. Man kan jämföra med skrivningen sinz för sins på G 164, där z-runan i de övriga ord där den förekommer uppenbarligen har ljudvärdet [ts]: guz Guðs, [aluaz] Hallvats. Här kan även nämnas Gutalagens $\operatorname{senz}=\operatorname{sins,~där~}$ <Z> enligt Pipping (1905-07, lxi) "torde ... beteckna ts [ ${ }^{*} \operatorname{senns}>{ }^{*}$ "sen[ $\left.[n] t s\right]$ ".

Att den stungna I-runan i G 173 har förbisetts beror säkert på att den variant som föreligger i denna inskrift tidigare har varit helt okänd på Gotland. Kanske kan den nu gjorda upptäckten leda till att fler exempel kommer i dagen.

\section{Bibliografi}

$\mathrm{DR}+\mathrm{nr}=$ inskrift publicerad i Danmarks runeindskrifter, av Lis Jacobsen och Erik Moltke, 3 vol.: Text; Atlas; Registre (København, 1941-42).

$\mathrm{G}+\mathrm{nr}=$ inskrift publicerad i Gotlands runinskrifter, d.v.s. SRI, 11-12. (Inskrifter med nummer högre än G 222 finns preliminärt behandlade i Gustavson och Snædal, manus.)

Gustavson, Helmer, och Thorgunn Snædal. Manus. "Gotlands runinskrifter, 3." (Tillgängligt som pdf-filer på Riksantikvarieämbetets webbsida https://www. raa.se/kulturarv/runor-och-runstenar/digitala-sveriges-runinskrifter/.)

Källström, Magnus. 2016. "Gravhällsfragmentet från Tornby i Fornåsa i Östergötland och utvecklingen av några medeltida runformer." Futhark 6 (2015): 107-142.

—. 2019a. "En tidigare okänd runform på Gotland." Riksantikvarieämbetet, K-blogg. Publicerat den 7 december 2019. http://www.k-blogg.se/2019/12/07/ en-tidigare-okand-runform-pa-gotland/

—. 2019b. ”Ett runristat blyföremål från Pryssgården, Östra Eneby sn, Östergötland.” Rapport, Antikvarisk-topografiska arkivet, Riksantikvarieämbetet, Stockholm (dnr 2019-529). Tryckt som bilaga 10 i: Pryssgården II mellan Östra stambanan och E4: Arkeologisk förundersökning: Östergötland län, Östergötland, Norrköpings kommun, Östra Eneby socken, Pryssgården 1:1, 1:13, Östra Eneby 178:1 (L2009:5959), Norrköping 339 (L2008:2266) och Norrköping 450 (L2008:8327), red. Marita Sjölin, 129-149. Statens historiska museer, Arkeologarna, Rapport 2019:24. Stockholm, 2019. 
—. Manus. "Runor i Halls kyrka."

Palumbo, Alessandro. 2012."Gutarunor: Studie i runformernas bruk och utveckling på Gotland under medeltiden och reformationstiden." Masteruppsats, Svenska språket/Nordiska språk VT 2012. Institutionen för nordiska språk, Uppsala universitet.

— . 2020. Skriftsystem i förändring: En grafematisk studie av de svenska medeltida runinskrifterna. Runrön, 23. Uppsala.

Pipping, Hugo. 1905-07. Guta lag och Guta saga jämte ordbok. Samfund til udgivelse af gammel nordisk litteratur, 33. København.

Snædal, Thorgunn. 2002. Medan världen vakar: Studier i de gotländska runinskrifternas språk och kronologi. Runrön, 16. Uppsala.

SRI = Sveriges runinskrifter. Olika författare; publicerade av Kungl. Vitterhets Historie och Antikvitets Akademien. 14 vol. hittills. Stockholm, 1900-.

SRI, 5 = Västergötlands runinskrifter, av Hugo Jungner och Elisabeth Svärdström (1940-70).

SRI, 11-12 = Gotlands runinskrifter, av Sven B. F. Jansson, Elias Wessen och Elisabeth Svärdström (1962-78). För nummer över G 222, se Gustavson och Snædal, manus.

U STERIK2002;168 = inskrift från Helgeandsholmen i Stockholm, publicerad på s. 167-169 i Laila Kitzler Åhfeldt och Magnus Källström, "Stockholmsrunor", i Upptaget: Arkeologi i Stockholm inför 2000-talet, red. Björn Hallerdt = S:t Eriks årsbok 2002: 167-180.

$\mathrm{Vg}+\mathrm{nr}=$ inskrift publicerad i Västergötlands runinskrifter, d.v.s. SRI, 5. 